\title{
Carbon Based Electronic Materials: \\ Applications in Electron Field Emission
}

\author{
J D Carey, R C Smith and S R P Silva \\ Advanced Technology Institute, University of Surrey, Guildford, GU2 7XH, United Kingdom
}

\begin{abstract}
The influence of the different types of bonding present in a range of carbon based materials is discussed as a precursor to describing the field emission characteristics of carbon cold cathode materials. Some of the controlling factors which govern electron emission from carbon based cathodes are discussed. It is shown that from disordered carbon films the interplay between the clustered $\mathrm{sp}^{2}$ phase and the insulating $\mathrm{sp}^{3}$ matrix is important. The transition from a 'back contact' to 'front surface' controlled emission mechanism is described in terms of the $\mathrm{sp}^{2}$ content and field penetration. A possible reason for high field enhancement factors found in disordered films also is provided. It is further shown that changes to the $\mathrm{sp}^{2}$ phase by current stressing can improve the field emission characteristics. Emission from carbon nanotubes is also discussed and the prospects for new types of nanotube - polymer composite based cathodes are also considered.
\end{abstract}




\section{Introduction}

Amongst the elements of the periodic table, carbon is unique in being able to form one of the hardest naturally occurring materials - diamond, as well as one of the softest - graphite. These materials possess, respectively, a $5.5 \mathrm{eV}$ energy band gap and a zero eV energy band gap, allowing the electronic properties to vary between those found in a wide gap semiconductor (or insulator) and those of a semi-metal. This very different behaviour can be traced to the bonding and the bond hybridizations that are present. In the case of $\mathrm{sp}^{3}$ hybridization, four $\sigma$ bonds, arranged at $109.5^{\circ}$ to each other allow for the tetrahedral bonding of diamond. It is these four bonds that are responsible for the high hardness found in diamond. By contrast, in the case of graphite, $\mathrm{sp}^{2}$ hybridized carbon is present in which three $\sigma$ bonds lie in-plane to three other carbon atoms at $120^{\circ}$ to each other. In addition, one $p_{z}$ orbital per atom perpendicular to the basal plane results in anisotropy in the electronic properties.

These bond hybridizations are not restricted to the crystalline forms of carbon, and are present in disordered amorphous carbon (a-C). Unlike diamond, where large single crystals are difficult to grow, often requiring high temperatures, amorphous carbon can be grown over large areas and at low temperatures. These two factors have spurred considerable research into the electronic applications of a-C and hydrogenated a-C (a-C:H) films [1]. From an electronic point of view, these films can be considered as a disordered mixed phase material consisting of a conductive $\mathrm{sp}^{2}$ phase, embedded in a less conductive $\mathrm{sp}^{3}$ matrix. The $\mathrm{sp}^{2}$ hybridized carbon atoms are usually in the form of nanometer-sized clusters, mainly in the form of rings or olephinic chains. These $\mathrm{sp}^{2}$ atoms give rise to occupied $\pi$ and unoccupied $\pi^{*}$ bands with the separation between the bands being related to the size of the cluster [2]. The $\mathrm{sp}^{3}$ component tends to be in the form of aliphatic chains of $\mathrm{C}$ atoms with $\mathrm{C}-\mathrm{C}$ and $\mathrm{C}-\mathrm{H}$ bonding being present. The optoelectronic properties, such as Tauc gap and Urbach energy, of a-C and a-C:H films are described in terms of transitions between the occupied $\pi$ states to the unoccupied $\pi^{*}$ states. As a result many of the optoelectronic properties (Raman, Tauc gap, photoluminescence) are associated with the clustering of the $\mathrm{sp}^{2}$ phase.

The interplay between $\mathrm{sp}^{2}$ and $\mathrm{sp}^{3}$ phases is also important for diamond, polycrystalline diamond and ultrananocrystalline diamond (UNCD). In these materials, the diamond grain is dominated by the $\mathrm{sp}^{3}$ phase with the grain boundary containing a higher fraction of $\mathrm{sp}^{2}$ bonded $\mathrm{C}$. The presence of the high energy band gap in diamond results in a small, and in the case of certain $\mathrm{H}$ terminated diamond surfaces, negative electron affinity (NEA). Low and negative electron affinities are advantageous for the emission of electrons under the action of an electric field, since the electron affinity acts as a measure of the potential barrier for emission. However, the low electron affinity, arising from the high electronic band gap, results in a small density of 
electrons in the conduction band. The grain boundary, present in polycrystalline and UNCD films, whilst possessing a lower energy gap, conversely has a higher barrier for emission. The transport of electrons between the grain and grain boundary is therefore important especially at the film-vacuum interface - the so-called triple junction [3].

Despite the high electron affinity (work function) in $\mathrm{sp}^{2}$ rich materials, carbon nanotubes (CNTs) [4], as well as carbon nanofibers [5], are attractive for electron sources due to the high aspect ratio inherent in these structures - Figure 1. CNTs are rolled up sheets of a graphene layer and depending on the chiral angle can be metallic or semiconducting. In addition to single-wall nanotubes, multiwall nanotubes, MWNTs, consisting of concentric tubes are also possible. CNTs can be produced by a number of different methods e.g. arc discharge methods, or by chemical vapor deposition (CVD). Both thermal and plasma enhanced CVD can be used, almost always accompanied by decomposition of a hydrocarbon species in the presence of a transition metal catalyst; $\mathrm{Ni}$ or Fe being the most commonly used. In the CVD process the catalyst is pretreated by thermal heating $[6,7]$ or laser nanostructuring [8] into islands. Such an approach tends to produce randomly arranged nanotubes which can have with a wide diameter distribution. Extensive studies have now confirmed that the properties of the catalyst often determine the properties of nanotube produced. Chhowalla et al. [9] and Poa et al. [10] have independently shown that the average diameter of MWNTs can be approximately $80 \%$ of the diameter of the catalyst islands on which they were grown. Etching in ammonia, can be used to produce a narrower size distribution of catalyst islands by removing those with a smaller diameter. However, such an approach fails to overcome the random nature and location of the islands and results in a random distribution of nanotubes. Vertical alignment of nanotubes is possible by plasma enhanced CVD growth in which an electric field (typically $<1 \mathrm{~V} / \mu \mathrm{m}$ ) is generated between the quasi-neutral plasma and the substrate. The extent of vertical alignment being determined by the rf power or self-bias generated [10]. A strong interaction between the catalyst and the underlying substrate tends to anchor the catalyst to the substrate resulting in 'base growth' nanotubes. A weaker catalyst - substrate will result in the catalyst migrating towards the tip of the nanotube - 'tip growth'. It should be recalled that the melting temperature of nanosized catalyst particles will be lower the melting temperature of bulk metal [11], this may result in melting of the catalyst particle during growth. How the different growth methods affect the type of electrical contact that is formed and whether the presence of metallic nanoparticles at the tip of the nanotube affects the resultant field emission is still a matter of debate. For positional control of nanotubes, e-beam lithographic deposition of the catalyst particle is required. A comprehensive study by Teo et al. [12] has showed how the number and diameter of vertically aligned CNTs depends on the initial catalyst diameter. E-beam lithography offers excellent 
degree of diameter and positional control, however, such a process is time consuming and, therefore, alterative parallel catalysts production methods are currently being explored

From crystalline and nanocrystalline diamond to amorphous carbon thin films and carbon nanotubes, the type of carbon bonding $\left(\mathrm{sp}^{2}\right.$ vs. $\left.\mathrm{sp}^{3}\right)$ and the method of material production has profound implications for the electronic properties of the respective carbon based material that is produced. Understanding how these electronic properties influence the field emission characteristics of these materials is therefore crucial for a field emission based device.

\section{Field Emission from Carbon Based Materials and Criteria for Practical Electron Sources}

The ability to extract electrons from a material has a ready number of applications ranging from field emission based displays (FEDs), requiring current densities of $10 \mathrm{~mA} / \mathrm{cm}^{2}$, to electron sources for microwave applications and X-ray sources. The latter require a current density in excess of $1-2 \mathrm{~A} / \mathrm{cm}^{2}$ in the $\mathrm{GHz}$ frequency range. Such applications are generally considered as being within the realm of vacuum micro- and nanoelectronics. Field induced electron emission from a surface is primarily determined by the strength of the local electric field and the potential barrier to emission. In a metal, the potential energy barrier corresponds to the work function of the material. For a semiconductor the barrier to emission from the conduction band can be estimated from the electron affinity. The local electric field is the field in the vicinity of the emitting structure and differs from the applied macroscopic field. In the usual two terminal diode configuration, an anode at potential $\mathrm{V}$, separated by a distance $\mathrm{D}$ from a grounded cathode, results in a macroscopic field of magnitude V/D. The local field is enhanced relative to this applied field and is characterised by the field enhancement factor or field magnification factor, $\beta$. For tip based emitters, such as CNTs, the enhancement factor depends on the geometric properties of the emitter, such as the height and radius [13]. With anode voltages, typically several thousands of volts, practical field emission devices, employ a third gate electrode which lies 1-2 $\mu \mathrm{m}$ away from the emitter. In such a configuration, the close proximity of the gate produces a sufficiently high gate field to initiate emission at low voltages $(<30 \mathrm{~V})$. Such low voltages can be readily switched with conventional electronics, which in turn allows for efficient matrix addressing. For a practical flat panel display it is necessary to have typically $100 \mathrm{Cd} / \mathrm{m}^{2}$ brightness but most field emission will exceed $300 \mathrm{Cd} / \mathrm{m}^{2}$. In general, emission current densities of $10 \mathrm{~mA} / \mathrm{cm}^{2}$ will be sufficient to give suitable output from conventional phosphor cathodes with ideally emission sites in excess of $10^{6} \mathrm{~cm}^{-2}$ in order to obtain uniform emission from a high density display without correction optics.

To understand the controlling factor for electron emission, three fundamental questions are worth consideration [14]. Firstly, what is the source of the electrons? Secondly, how are the 
electrons transported through the film? Finally, how are the electrons emitted into the vacuum? Table 1 addresses these questions for a range of cathode systems.

(i) Metallic emitters.

Consider the case of a flat metallic emitter such as Mo or W. The high density of electron states at the Fermi level allows for a sufficiently high supply of electrons. In this case the rate limiting step is electron tunnelling though the potential barrier formed by the work function (typically 4 $5 \mathrm{eV}$ ) under the influence of the applied electric field. Such tunnelling is described within the Fowler-Nordheim formulism. For a flat metal surface i.e. one in which there are no significant asperities, the enhancement factor can be taken as unity, and efficient tunnelling will require

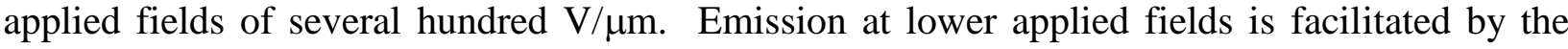
production of metallic tip based emitters, such as Spindt tips, in which the inherent aspect ratio acts to concentrate the applied electric field. Whilst field emission arrays of Spindt tips have been fabricated, the problems of the scalability and lithography required for large area displays, have acted as a catalyst for alternative large area emitters.

\section{(ii) Amorphous Carbon Cathodes}

Cold cathodes based on amorphous carbon have attracted particular attention since it is possible to deposit a-C thin films over large areas and at low temperatures. This latter point is of notable importance since it permits deposition onto organic or plastic substrates. In addition, the softening temperature of most common display glass is around $400^{\circ} \mathrm{C}$ and as a result deposition processes which significantly exceed this temperature are not compatible with current technology. Fortunately, the low temperature deposition of amorphous carbon makes it an ideal candidate as a potential cathode material. Early interest in carbon films as cold cathodes was driven by the hope that these films possessed negative electron affinity in the same way that certain $\mathrm{H}$ terminated diamond films can possess a NEA surface. As a result, once electrons are injected into the conduction band of the film, there would be a steady supply of electrons which can emerge at the film/vacuum interface.

It is worth categorizing several types of amorphous carbon films for the analysis of their electron field emission characteristics. Progressing with ascending energies required for the growth of the films, we will consider emission from

(i) polymer-like amorphous carbon (PAC), which are soft films with a high resistivity, high optical gap and low density of $\mathrm{sp}^{2}$-related defects states,

(ii) Diamond-like carbon (DLC), a harder film, often containing $\mathrm{H}$ with an $\mathrm{sp}^{3}$ content usually up to $60 \%$, often produced by PECVD, 
(iii) Tetrahedral amorphous carbon film (ta-C), a hard film with high density of defect states and an $\mathrm{sp}^{3}$ content of up to $88 \%$. These films are usually produced by cathodic arc methods.

It is also worth discussing that in the case of a-C films that do not possess large numbers of defect states within the films or graphitic or conducting regions in its microstructure, a conditioning process is often required before the onset of emission of electrons takes place [15]. Subsequent to the initiation voltage required in the conditioning, emission takes place at successively lower threshold fields which reaches a minimum value after about four cycles. The hysteresis observed in this process of conditioning is shown clearly in Fig. 2, and is nonreversible; i.e. once a cathode has been fully conditioned it will remain conditioned despite the surface being examined days later even after exposure to atmospheric conditions.

Since there are different types of a-C and $\mathrm{a}-\mathrm{C}: \mathrm{H}$ film possible with very different properties, it is not surprising that there is more than one possible emission mechanism. One immediate feature for the need of different models concerns the application of an electric field to the surface of a semiconductor. It is well known that the degree of field penetration into a semiconductor film depends on the conductivity of the sample. The higher the conductivity the smaller the extent that the externally applied field will penetrate into the film. In the ultimate limit of a metallic conductor, there will be no penetration of the field into the film. As the $\mathrm{sp}^{2}$ phase is associated with the more conductive clusters within the film, the field lines from the anode will terminate on these clusters. As a result there is an immediate link between the emission mechanism and the extent of field penetration. In some cases field penetration will extend to the film/substrate interface - where the emission mechanism will be referred to as a 'back contact' controlled. Such an emission mechanism differs in films for which there is little field penetration and where the emission is controlled by the properties at or near to the front of the film/vacuum interface - referred to as the 'front surface' controlled mechanism. The origin of these two different types of mechanism will be explored in detail below.

For PAC films, the density of conductive $\mathrm{sp}^{2}$ states near the Fermi level [16] is low $\left(<10^{18}\right.$ $\mathrm{cm}^{-3}$ ) and the field lines from the anode are able to penetrate into the film. Forrest et al. reported for such films, a variation of the threshold field for emission with film thickness and explained this observation by proposing an interlayer model based on space charge induced band bending at the back contact. [17] In this model the a-C film acts as an interlayer with the true cathode being the underlying Si or metal substrate, with the crucial factor being the heterojunction that formed at the back contact. [18]

In the case of DLC and ta-C films the density [16] of unpaired electron states near to the Fermi level is higher $\left(10^{20} \mathrm{~cm}^{-3}\right)$. These films have a high $s p^{2}$ content as well as a large band gap 
$(>2 \mathrm{eV})$ and as a consequence the wavefunction overlap of the clusters will result in electron delocalization [19] and/or enhanced hopping between the clusters that will enhance the connectivity, as shown in Fig. 3. Application of an external electric field results in extraction of electrons from the film surface. Replenishment of the emitted electrons to the surface layer is accomplished due to the good connectivity between the clusters. Emission from these high $s p^{2}$ rich films can be characterised as a "front surface"-type emission [20]. It is known from atomic force microscope images of DLC films that they are atomically flat, with a typical rms roughness of less than $1 \mathrm{~nm}$. If a Fowler-Nordheim emission process is present then it is necessary to explain the large enhancement factors, typically several hundred $\square$ required to lower a barrier by $4 \mathrm{eV}$. High resolution scanning tunneling microscope (STM) study of the DLC films have shown [21] that the conductivity of the film is not uniform with a number of localized high conductivity regions of a few nm in size surrounded by a more insulating matrix. These STM results can be interpreted as resulting from a series of closely spaced localized conductive $\mathrm{sp}^{2}$ regions which, under the action of the applied field allows electrons to hop from one spatially localized cluster to another as shown in Fig. 3.

We propose the enhancement of the applied field is due to the different intrinsic dielectric and conductive properties of nanometer sized $\mathrm{sp}^{2}$ clusters embedded in the surrounding $\mathrm{sp}^{3}$ insulating matrix. It is well known that the electric field near a single conductive dielectric sphere in a insulating matrix, is increased by a factor of up to two due to the dielectric mismatch between the sphere and the matrix. It has been calculated [22] that the presence of two closely spaced spheres with the conductivity of gold, an enhancement of the electric field by a factor of 56 is possible if the spheres have a separation of $5 \mathrm{~nm}$. This enhancement increases as the separation between the spheres is reduced reaching a factor of 400 for a sphere-sphere separation of $1 \mathrm{~nm}$. Although the conductivity of the $\mathrm{sp}^{2}$ clusters will not be as high as Au, these calculations demonstrate that high enhancement factors can be obtained by considering the effects of just two conductive spheres near the surface.

In this manner, the emission process for DLC and ta-C films can be explained as follows: the high density of defects will act to localise and attract the field lines from the anode to a thin region near the surface of the film. High field enhancement factors are present if two (or more) $\mathrm{sp}^{2}$ conductive clusters are nearby. Once the electrons are emitted from the clusters near the surface of the film, they can be replaced, by electrons from clusters deeper within the film. Such a description aids us in explaining the non-uniform (on the nano- to microscale) nature of the emission across the surface of the film in which the local arrangement of the clusters below the surface is important. Figure 4 shows the transition from back-contact to front surface controlled emission for different types of a-C film. 


\section{Field Emission as a Function of Conditioning and Post Growth Modifications}

We have previously discussed conditioning - the need to apply several voltage cycles before the onset of stable emission occurs (c.f. Fig. 2). Similar conditioning treatments have also been reported necessary in tetrahedral amorphous carbon (ta-C) and in diamond films grown by chemical vapour deposition. [23] The exact nature of this conditioning step and the role of any damage-induced surface microprotrusions is not fully understood. However, conditioning may involve an increase in the concentration of threefold coordinated carbon atoms at the expense of fourfold coordinated atoms. For practical carbon based display applications, the value of the threshold field must be as reproducible as possible. Furthermore, to limit the spread in the drive voltages, the hysteresis in the current-voltage (I-V) characteristics should be kept to a minimum. Current stressing has been shown to overcome the need for a voltage controlled conditioning cycle. It should be noted that in improperly conditioned films there may be significant differences in current between the upward voltage cycle or the downward cycle. As a measure of this 'hysteresis effect', the difference in the applied fields between the upward and downward voltage cycles at a current of $1 \mathrm{nA}$ is used. For a series of polymer-like films, current stressing of the films was performed by contacting the anode (which is controlled by a manipulator) to the film and passing a current through the film up to a pre-determined level. Each film was tested before stressing by applying a field of up to $100 \mathrm{~V} / \mu \mathrm{m}$ and only those samples which did not emit after this preliminary test were subject to further investigation. For the current stressing measurements several identical films from the same deposition run were examined. For reference the typical value of $\mathrm{E}_{\text {th }}$ for films which did emit after conventional (or field induced) conditioning is about $30 \mathrm{~V} / \mu \mathrm{m}$.

The three current stress levels chosen were $10^{-8}, 5.2 \times 10^{-8}$ and $2 \times 10^{-7} \mathrm{~A}$. The FE characteristics of the film stressed to $10^{-8} \mathrm{~A}$ (not shown) exhibited emission but with an $\mathrm{E}_{\mathrm{th}}$ of over $85 \mathrm{~V} / \mu \mathrm{m}$ and a full width (at half maximum) of the first cycle hysteresis loop of over 20 $\mathrm{V} / \mu \mathrm{m}$. Subsequent voltage cycles resulted in a reduction of $\mathrm{E}_{\mathrm{th}}$, though the average threshold field obtained from the latter three cycles was $66 \pm 4 \mathrm{~V} / \mu \mathrm{m}$. Stressing to a higher current of $5.2 \mathrm{x}$ $10^{-8} \mathrm{~A}$ results in an initial emission at a field of $48 \mathrm{~V} / \mu \mathrm{m}$, coupled with a width in the $\mathrm{I}-\mathrm{V}$ characteristics of $20 \mathrm{~V} / \mu \mathrm{m}$, as shown in Fig. 5. The I-V characteristics of the film before stressing is also presented and shows that no emission has occurred from this film even up to fields of $90 \mathrm{~V} / \mu \mathrm{m}$. The threshold field continues to decrease after subsequent voltage cycles and finally reached $40 \mathrm{~V} / \mu \mathrm{m}$ after the $4^{\text {th }}$ cycle. The average value of $\mathrm{E}_{\mathrm{th}}$ obtained from this film is 38 $\pm 10 \mathrm{~V} / \mu \mathrm{m}$, higher than that obtained from a film which underwent the conventional conditioning treatment. Since the width of the first cycle is $20 \mathrm{~V} / \mu \mathrm{m}$ the film is not fully conditioned. The I- 
$\mathrm{V}$ characteristic of the film stressed to $2 \times 10^{-7} \mathrm{~A}$ is shown in Fig. 6 where the value of $\mathrm{E}_{\mathrm{th}}$ for the $1^{\text {st }}$ cycle was $34 \mathrm{~V} / \mu \mathrm{m}$, which subsequently decreased to 30,26 and $27 \mathrm{~V} / \mu \mathrm{m}$ in the remaining three cycles. The average value of $E_{\text {th }}$ of $28 \pm 2 \mathrm{~V} / \mu \mathrm{m}$ is comparable to the value of $\mathrm{E}_{\mathrm{th}}$ for films which have undergone a conventional conditioning treatment. The width of the I-V hysteresis loop is about $2 \mathrm{~V} / \mu \mathrm{m}$ in each run and no evidence of a conditioning cycle after current stressing is observed. Since the FE characteristics are different and are observed to improve with higher stress currents, the mechanical effects of contacting between the anode and film as the primary reason for the improvements can be eliminated.

In order to examine whether the current induced conditioning was permanent, the films were retested some hours after the initial stressing had been performed. In order to prevent any possible atmospheric contamination the samples remained held under vacuum during this period. Retesting of the sample that was stressed to $5.2 \times 10^{-8} \mathrm{~A}$, showed that $\mathrm{E}_{\mathrm{th}}$ rose to about $50 \mathrm{~V} / \mu \mathrm{m}$, similar to the value obtained in the first cycle after this sample had just been stressed, indicating some form of 'healing' process had occurred. By contrast in the film stressed to $2 \times 10^{-7} \mathrm{~A}$, no evidence of a conditioning cycle is required 23 or 87 hours after the original current stressing had been performed.

In the study by Mercer et al. [24] a scanning tunnelling microscope tip was used to effectively current stress ta-C films by generating a highly spatially localised electric field. They observed that after ramping the tip-sample bias and current, nanostructures of about $100 \mathrm{~nm}$ in extent form. By using high resolution spatially-resolved electron energy loss spectroscopy they showed that the bonding configuration changes from predominately four-fold coordinated $\mathrm{C}$ to three-fold coordinated. The net effect of the conditioning or the current stressing treatments may well be to generate conductive $\mathrm{sp}^{2}$ rich areas either in the form of filaments or clusters through localized Joule heating. It is also possible to improve the field emission properties by the controlled introduction using ion implantation. Morell et al. used energetic Fe and Si ions implanted into microcrystalline diamond and UNCD [25]. On the basis of changes in Raman spectra they reported changes in the trigonal - tetragonal network where irradiation resulted in the formation of graphitic nanochannels. The small diameter nanochannels results in an improved field enhancement factors and are of sufficient size to be able to withstand the current densities generated during emission. Changes in the bonding configuration indicate an improvement in the threshold field. No significant changes in the field emission behaviour was reported for irradiated S doped UNCD films; this was attributed to the existence of an extensive trigonal network forming during growth. [26] 


\section{Carbon Nanotube based Emitters}

Despite the high work function of graphite materials (typically $4.5-5 \mathrm{eV}$ ), the high aspect ratio of nanotubes acts to concentrate the field lines from the anode. Typically, emission from such materials occurs at local fields of a few V/nm. Two important factors affect the emission characteristics from nanotubes. Firstly, variations in the height and radius of the nanotube results in a distribution of enhancements factors. As a result, different nanotubes will emit at different applied fields. Secondly, the proximity of nearby nanotubes can have profound effects on the emission. Figure 7 shows simulations of the emission current as a function of inter-nanotube spacing for a nanotube $4 \mu \mathrm{m}$ in length. It can be seen that when the inter-nanotube separations is 1 or $2 \mu \mathrm{m}$, low levels of current and high applied anode voltages are required for emission. However, as the separation between the nanotubes increases the anode voltage required for emission decreases and the overall current level increases. Furthermore, the current levels and threshold anode voltages for 8, 16 and $32 \mu \mathrm{m}$ inter-nanotube separation are almost identical. This suggests that the ideal inter-nanotube separation is about twice the height of the individual nanotube. When the density of nanotubes is high screening of the applied field occurs which results in poor emission efficiency. Experimental evidence for the effects of field screening have been reported by Nilsson et al. [27] in mats of nanotubes.

Optimizing emission from CNTs is an important technological goal due to the relatively high current production costs of nanotubes. The effects of screening coupled with the tendency of nanotubes to clump together means that a sizeable fraction of emitters are not participating in emission. One way to increase the fraction of emitting nanotubes and encourage efficient dispersal is in the use of composite cathodes. Field emission from undoped and B doped MWNTs embedded in polystyrene has been previously reported [28]. It was shown that the threshold field for emission increased with nanotube concentrations for mass fractions in the range of $11-33 \%$. This increase in threshold field with mass fraction was attributed to screening and suggests that lower concentration of nanotubes should be employed. In addition, to the opportunity of using smaller amounts of CNTs, employing a composite cathode structure will aid in the protection of the cathode from bombardment by gas molecules. It is also possible for a ballast layer, to limit the amount of current drawn, to be readily incorporated [29].

Embedding the emitter material in a host follows the early work of Latham [30], and led the way to the development of metal-insulator-metal-insulator-vacuum (MIMIV) cathodes consisting of conductive graphitic particles into a non-conductive epoxy matrix to form cathodes [31]. In these electrically inhomogeneous cathodes, tailoring the concentration of the conductive phase, as a means to control charge transport, is important. Such cathodes are therefore 
reminiscent of the intrinsically electrically inhomogeneous cathodes, such as diamond-like carbon (DLC) thin films discussed earlier.

\section{Conclusions}

The rich variety of carbon based materials that can be produced allows for an enviable ability to adjust the properties of thin films. Complications can exist when comparing one type of film with another but a fundamental understanding of the differences between the $\mathrm{sp}^{2}$ and $\mathrm{sp}^{3}$ phases is crucial in understanding the electronic properties of the films. This understanding is particularly important in using carbon based materials as electron sources. New types of carbon emitters are emerging with carbon nanotubes being considered particularly attractive with high current densities at low applied field possible. Screening effects and increasing the participation of the nanotubes will be important in future applications of carbon cold cathode devices.

\section{Acknowledgements}

The authors would like to thank the Engineering Physical Sciences Research Council (UK) for funding. JDC acknowledges EPSRC for an Advanced Research Fellowship. 


\section{References}

1 S. R. P. SILVA, J. D. CAREY, R. U. A. KHAN, E. G. GERSTNER, and J. V. ANGUITA, in Handbook of Thin Film Materials, edited by H. S. Nalwa, (Academic Press, New York, 2002), Vol. 4, Chap. 9, pp. 403-506.

2 G. FANCHINI and A. TALIAFERRO, Appl. Phys. Lett. 85, (2004) 730.

3 I. ALEXANDROU, E. KYMAKIS and G.A.J. AMARATUNGA, Appl. Phys. Lett. 80, (2002) 1435.

4 J-M BONARD, J-P. SALVETAT, T. STOCKLI, W. A. DE HEER, L. FORRO, and A. CHATELIN, Appl. Phys. Lett. 73, (1998) 918.

5 R. C. SMITH, J. D. CAREY, C. H. P. POA, D. C. COX and S. R. P. SILVA, J. Appl. Phys. 95, (2004) 3153.

6 V. I. MERKULOV, D. H. LOWNDES, Y. Y. WEI, G. ERES, and E. VOELKL, Appl. Phys. Lett. 76, (2000) 3555.

7 J. D. CAREY, L. L. ONG, and S. R. P. SILVA, Nanotechnology 14, (2003) 1223.

8 S. J. HENLEY, C. H. P. POA, A. A. D. T. ADIKAARI, C. E. GIUSCA, J. D. CAREY, and S. R. P. SILVA, Appl. Phys. Lett. 84, (2004) 4035.

9 M. CHHOWAlla, K. B. K. TEO, C. DUCATI, N. L. RUPESINGHE, G. A. J. AMARATUNGA, A. C. FERRARI, D. ROY, J. ROBERTSON and W. I. MILNE, J. Appl. Phys. 90, (2001) 5308.

10 C.H.P. POA, S.J. HENLEY, G.Y. CHEN, A.A.D.T. ADIKAARI, C.E. GIUSCA and S.R.P. SILVA, J. Appl. Phys. 97, (2005) 114308.

11 S. J. HENLEY, J. D. CAREY, and S. R. P. SILVA, Phys. Rev. B 72, (2005) 195408.

12 K.B.K. TEO, S.B. LEE, M. CHHOWALlA, V. SEMET, V.T. BINH, O. GROENING, M. CASTIGNOLleS, A. LOISEAU, G. PIRIO, P. LEGAGNEUX, D. PRIBAT, D. G. HASKO, H. AHMED, G.A.J. AMARATUNGA and W.I. MILNE, Nanotechnology 14, (2003) 204. 
13 R. C. SMITH, R. D. FORREST, J. D. CAREY, W. K. HSU and S. R. P. SILVA, Appl. Phys. Lett. 87, (2005) 013111.

14 J.D. CAREY, Phil. Trans. Roy. Soc. A 361, (2003) 2891.

15 J. D. CAREY and S. R. P. SILVA, Appl. Phys. Lett. 78, (2001) 347.

16 M. COLLINS, R. C. BARKLIE, J. V. ANGUITA, J. D. CAREY and S. R. P. SILVA, Diamond Relat. Mater. 9, (2000) 781.

17 R.D. FORREST, A. P BURDEN, S.R.P. SILVA and X. SHI, Appl. Phys. Lett. 73, (1998) 3784.

18 G. A. J. AMARATUNGA and S. R. P. SILVA, Appl. Phys. Lett. 68, (1996) 2529.

19 R.U.A. KHAN, J.D. CAREY, S.R.P. SILVA, B.J. JONES AND R.C. BARKLIE, Phys. Rev. B 63, (2001) 121201; S.R.P. SILVA and J.D. CAREY, Diam. Relat. Mater. 12, (2003) 151.

20 J. D. CAREY, R. D. FORREST, and S. R. P. SILVA, Appl. Phys. Lett. 78, (2001) 2339.

21 J. D. CAREY and S. R. P. SILVA, Phys. Rev. B 70, (2004) 235417.

22 P. C. CHAUMET and J. P. DUFOUR, J. Electrost. 43, (1998) 145.

23 A. A. TAlin, T. E. FELTER, T. A. FRIEDMANN, J. P. SUlliVAN, and M. P. SIEGAL, J. Vac. Sci. Technol. A 14, (1996) 1719.

24 T. W. MERCER, N. J. DINARDO, J. B. ROTHMAN, M. P. SIEGAL, T. A. FRIEDMANN, and L. J. MARTINEZ MIRANDA, Appl. Phys. Lett. 72, (1998) 2244.

25 A. GONZÁLEZ-BERRÍOS, D.HUANG, N.M. MEDINA-EMMANUELLI, K.E. KRISTIAN, O.O. ORTIZ, J.A. GONZÁLEZ, J.DE JESÚS, I.M. VARGAS, B.R. WEINER and G. MORELL, Diam. Relat. Mater. 13, (2003) 221.

26 G MORELL, A GONZALEZ-BERRIOS, B R WEINER and S GUPTA, Journal of Material Science:Materials in Electronics - this edition.

27 L. NILSSON, O. GROENING, C. EMMENEGGER, O. KUETTEL, E. SCHALLER, L. SCHLAPBACH, H. KIND, J-M. BONARD, and K. KERN, Appl. Phys. Lett. 76, (2000) 2071.

28 C. H. POA, S.R.P. SILVA, P.C.P. WATTS, W. K. HSU, H. W. KROTO and D.R.M. WALTON, Appl. Phys. Lett. 80, (2002) 3189. 
29 R. C. SMITH, J. D. CAREY, R. J. MURPHY, W. J. BLAU, J. N. COLEMAN and S. R. P. SILVA, Appl. Phys. Lett. 88, (2005) 263105.

30 R. V. LATHAM, High Voltage Vacuum Insulation, The Physical Basic, Academic Press, London, 1981.

31 A. P. BURDEN, H. E. BISHOP, M. BRIERLEY, J. M. FRIDAY, C. HOOD, P. G. A. JONES, A. Y. KHAZOV, W. LEE, R. J. RIGGS, V. L. SHAW, and R. A. TUCK, J. Vac. Sci. Technol. B 18, (2000) 900. 


\section{Figure captions}

Figure 1. A mat of multiwall carbon nanotubes produced by the arc discharge method.

Figure 2. Emission current versus macroscopic electric field for a $67 \mathrm{~nm}$ thick a-C:H film. The applied field is cycled up and down four times indicated by $(O)$ for run $1,(\square)$ for run 2 , (•) for run 3 and $(\nabla)$ for run 4.

Figure 3. Schematic of the transport process for PAC and DLC films. At the higher energy conditions hopping is easier as the concentration of hopping centres increases and their separation decreases.

Figure 4. Evolution from back-controlled to front surface control field emission for different types of carbon based cathodes. The optical gap is a measure of the band gap, reflecting the conductivity of the material.

Figure 5. Emission current versus electric field for films stressed to $I_{s}=5 \times 10^{-8}$ A. The applied field is cycled up and down four times as indicated by $(O)$ for run $1,(\square)$ for run $2,(\bullet)$ for run 3 and $(\nabla)$ for run 4 . The emission current for the film before stressing is indicted by $(\boldsymbol{\square})$. Not all data points are shown for clarity.

Figure 6. Emission current versus electric field for films stressed to $I_{s}=2 \times 10^{-7}$ A. The applied field is cycled up and down four times as indicated by $(\bigcirc)$ for run $1,(\square)$ for run $2,(\bullet)$ for run 3 and $(\nabla)$ for run 4 . The emission current for the film before stressing is indicted by $(\mathbf{\square})$. Not all data points are shown for clarity. 
Figure 7 Emission current as a function of applied voltage for a $4 \mu \mathrm{m}$ long nanotubes as a function of inter-nanotube separation. 
Table 1: Origin, transport and emission mechanism from a range of carbon based cathodes

\begin{tabular}{|l|l|l|l|}
\hline Material & Originate & Transport & Emission \\
\hline Flat Metal & $\begin{array}{l}\text { High DOS at } \\
\mathrm{E}_{\mathrm{F}}\end{array}$ & $\mathrm{n} / \mathrm{a}$ & $\begin{array}{l}\text { Fowler-Nordheim (FN) } \\
\text { Work function }(4-5 \mathrm{eV}) \\
(\beta=1)\end{array}$ \\
\hline Spindt tip & $\begin{array}{l}\text { High DOS at } \\
\mathrm{E}_{\mathrm{F}}\end{array}$ & $\mathrm{n} / \mathrm{a}$ & $\begin{array}{l}\text { Fowler-Nordheim } \\
\text { Work function }(4-5 \mathrm{eV}) \\
(\beta>50-100)\end{array}$ \\
\hline $\begin{array}{l}\text { Insulator/ wide gap } \\
\text { semiconductors } \\
\text { (Diamond, AIN) }\end{array}$ & Substrate & $\begin{array}{l}\text { Via Conduction band } \\
\text { or defect level }\end{array}$ & $\begin{array}{l}\text { Negative electron affinity, } \\
\text { Fowler-Nordheim }\end{array}$ \\
\hline $\begin{array}{l}\text { Diamond-like } \\
\text { carbon }\end{array}$ & Substrate & Hopping & $\begin{array}{l}\text { FN + field penetration } \\
\text { negligible }\end{array}$ \\
\hline $\begin{array}{l}\text { Polymer-like a-C } \\
\text { Folym }\end{array}$ & Substrate & Space charge effects & $\begin{array}{l}\text { FN + field penetration } \\
\text { important }\end{array}$ \\
\hline Carbon nanotubes & Substrate & Via the tube & $\begin{array}{l}\text { Fowler-Nordheim } \\
\text { Work function (4 - 5 eV) } \\
(\beta>200, \text { aspect ratio) }\end{array}$ \\
\hline $\begin{array}{l}\text { CNT - polymer } \\
\text { composites }\end{array}$ & $\begin{array}{l}\text { Substrate, } \\
\text { CNT }\end{array}$ & Percolation & Transport and FN \\
\hline
\end{tabular}




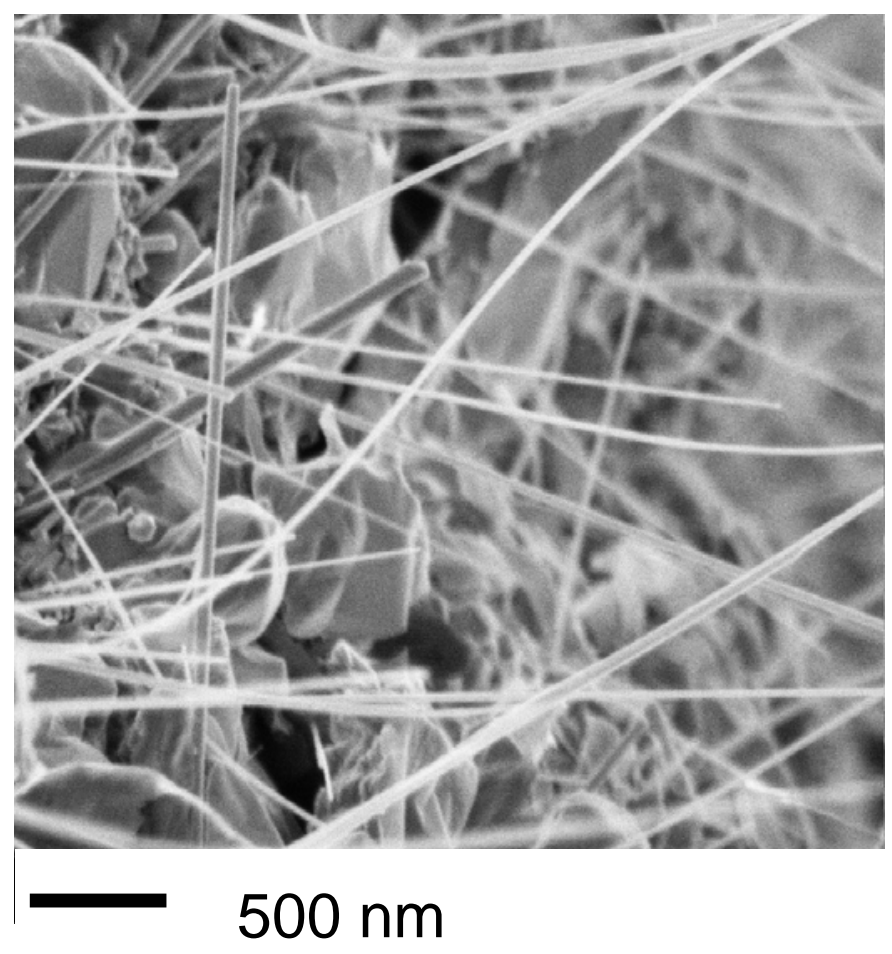

Figure 1 Carey 


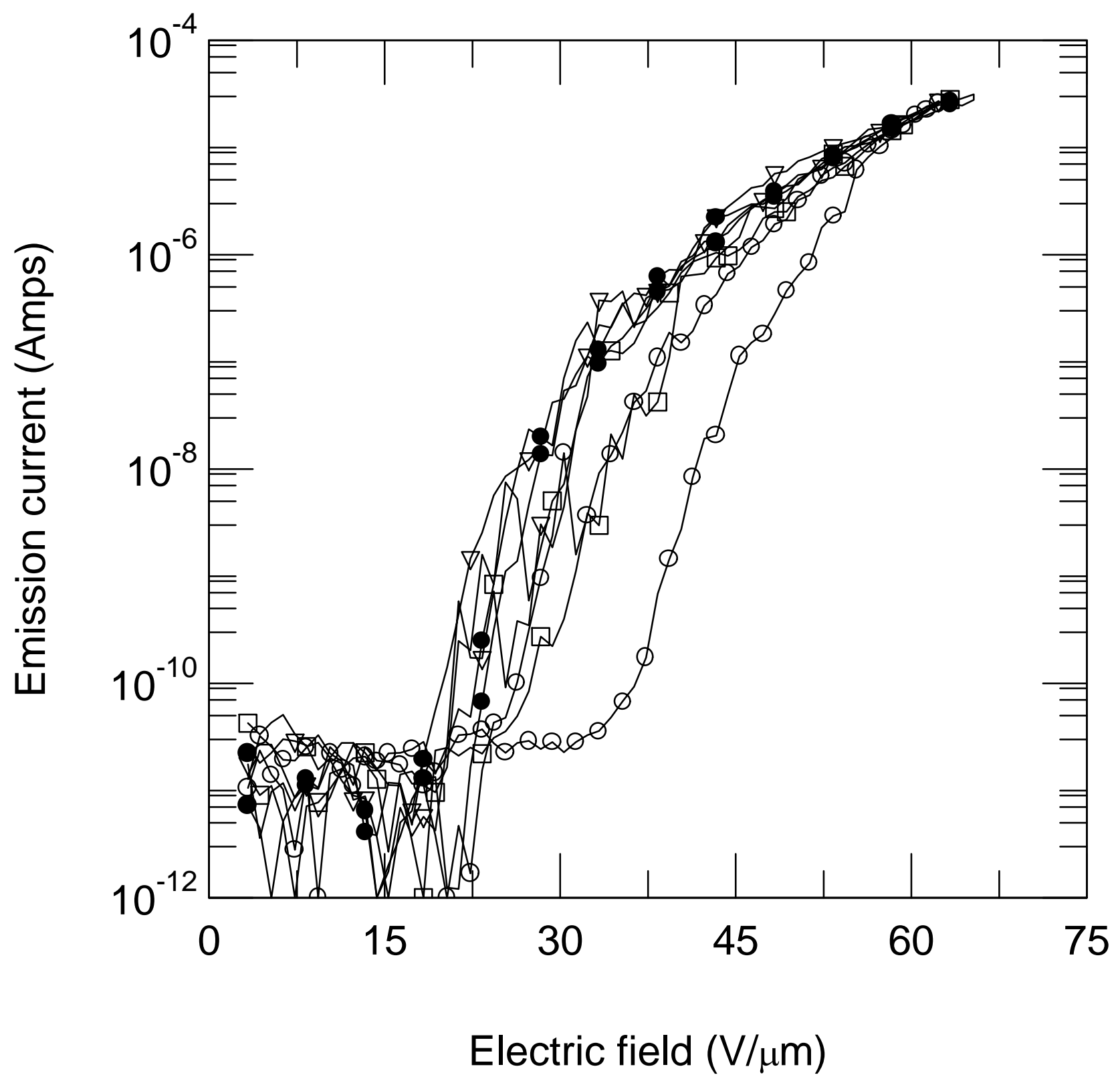

Figure 2 Carey 


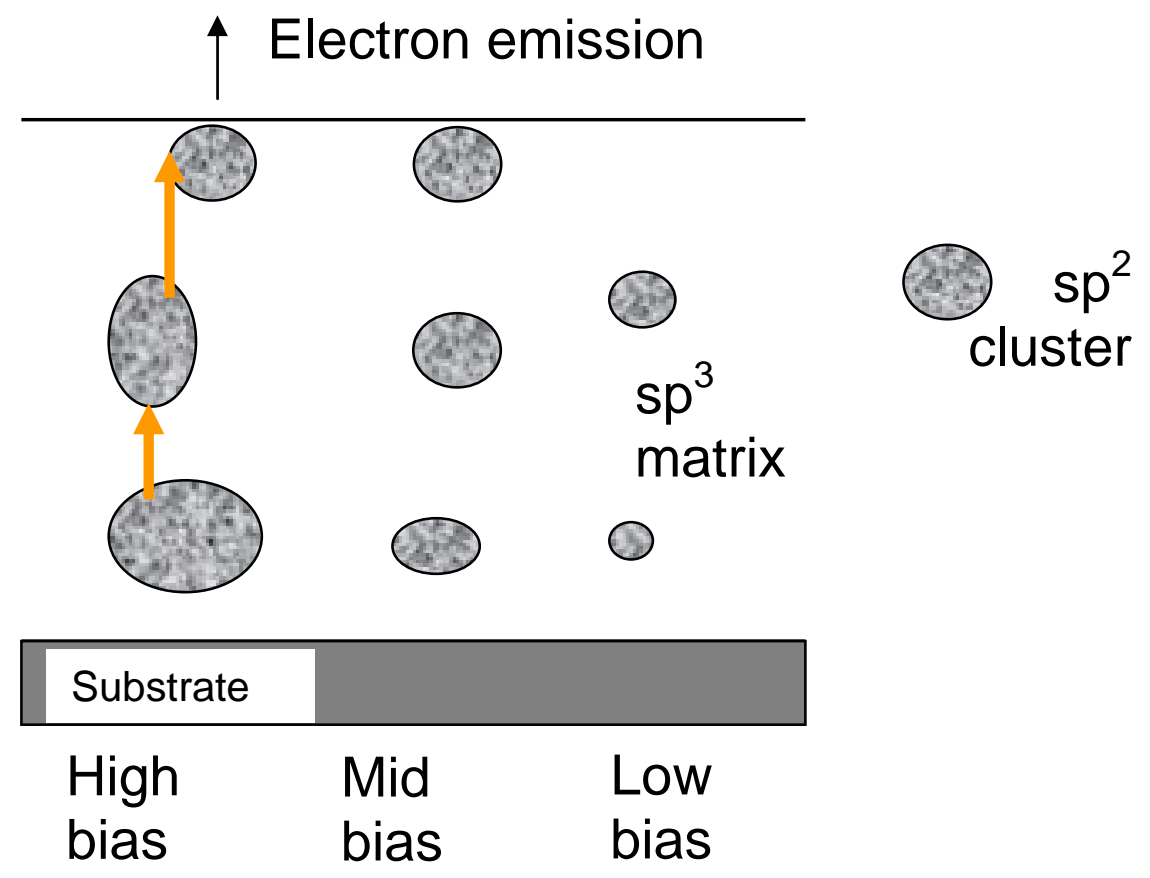

Figure 3 Carey 


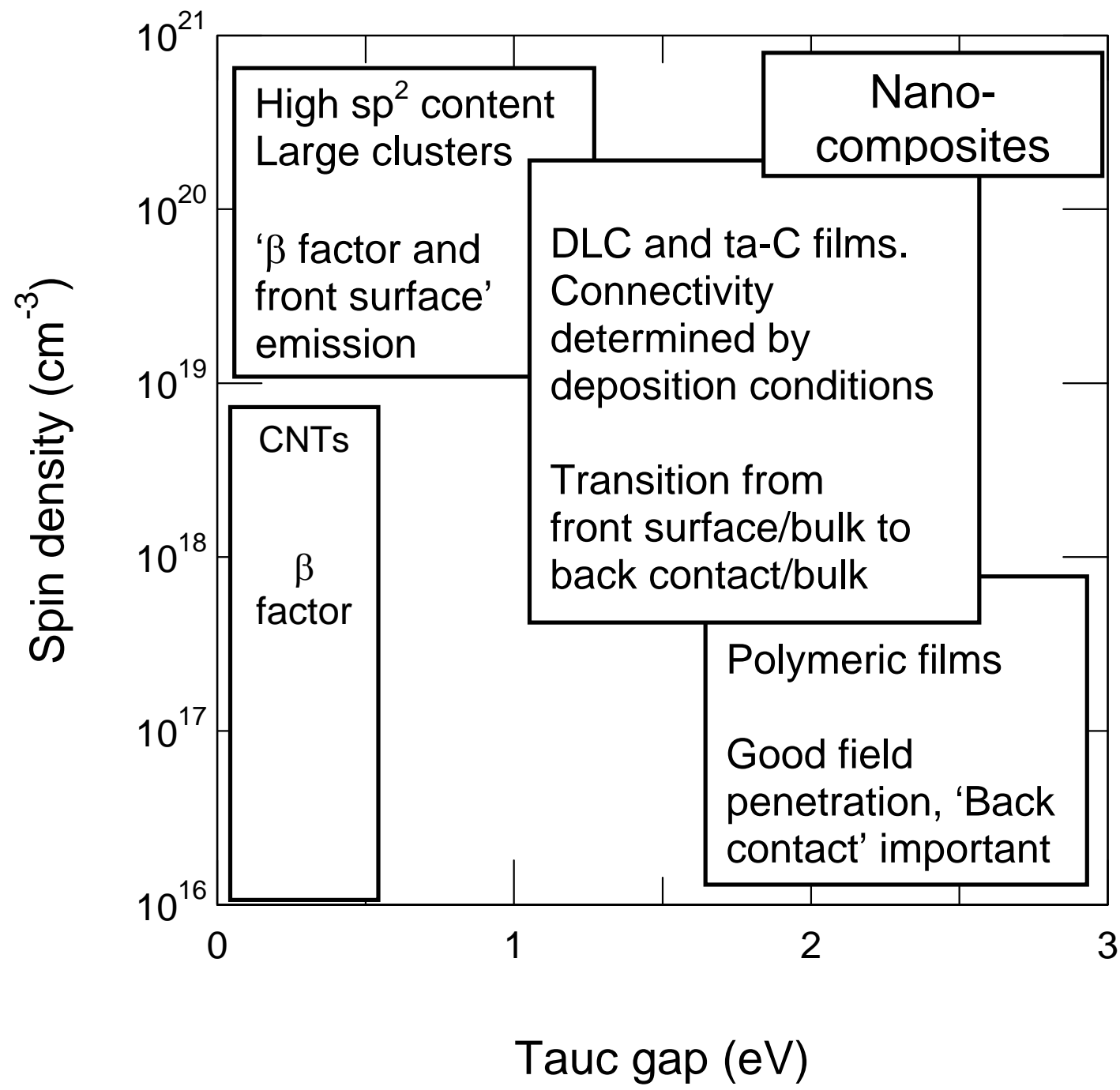

Figure 4 Carey 


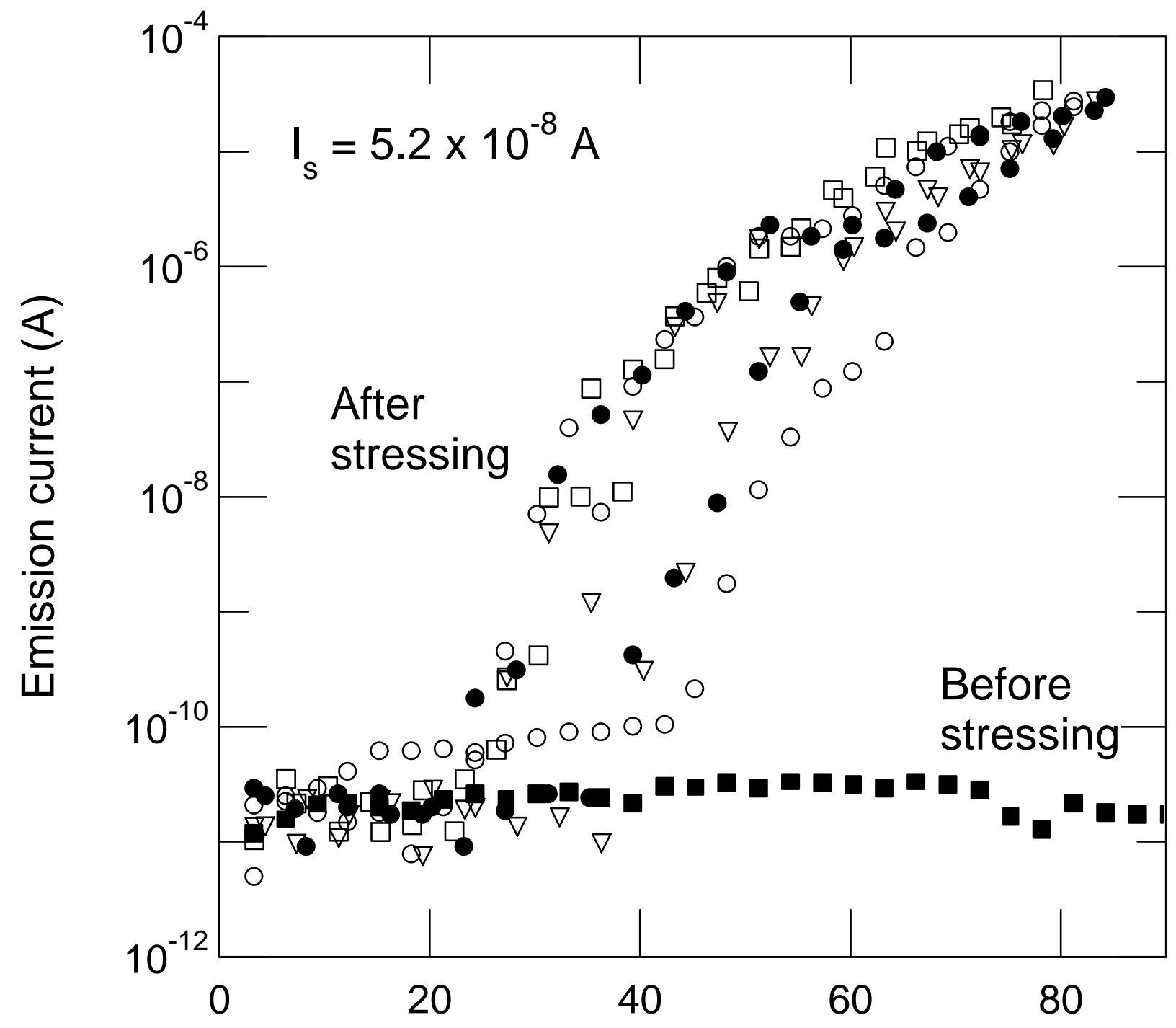

Electric field $(\mathrm{V} / \mu \mathrm{m})$

Figure 5 Carey 


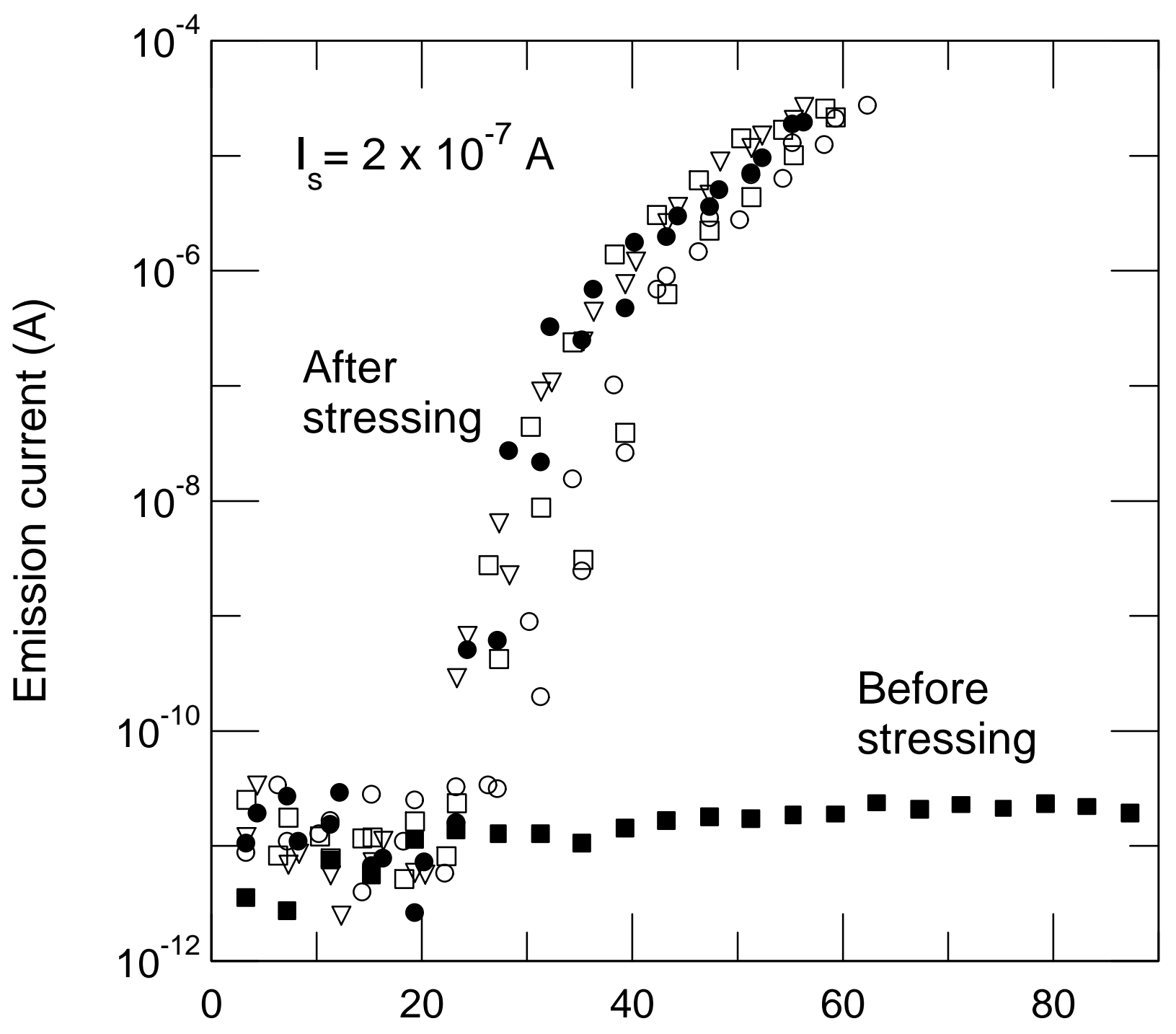

Electric field $(\mathrm{V} / \mu \mathrm{m})$

Figure 6 Carey 


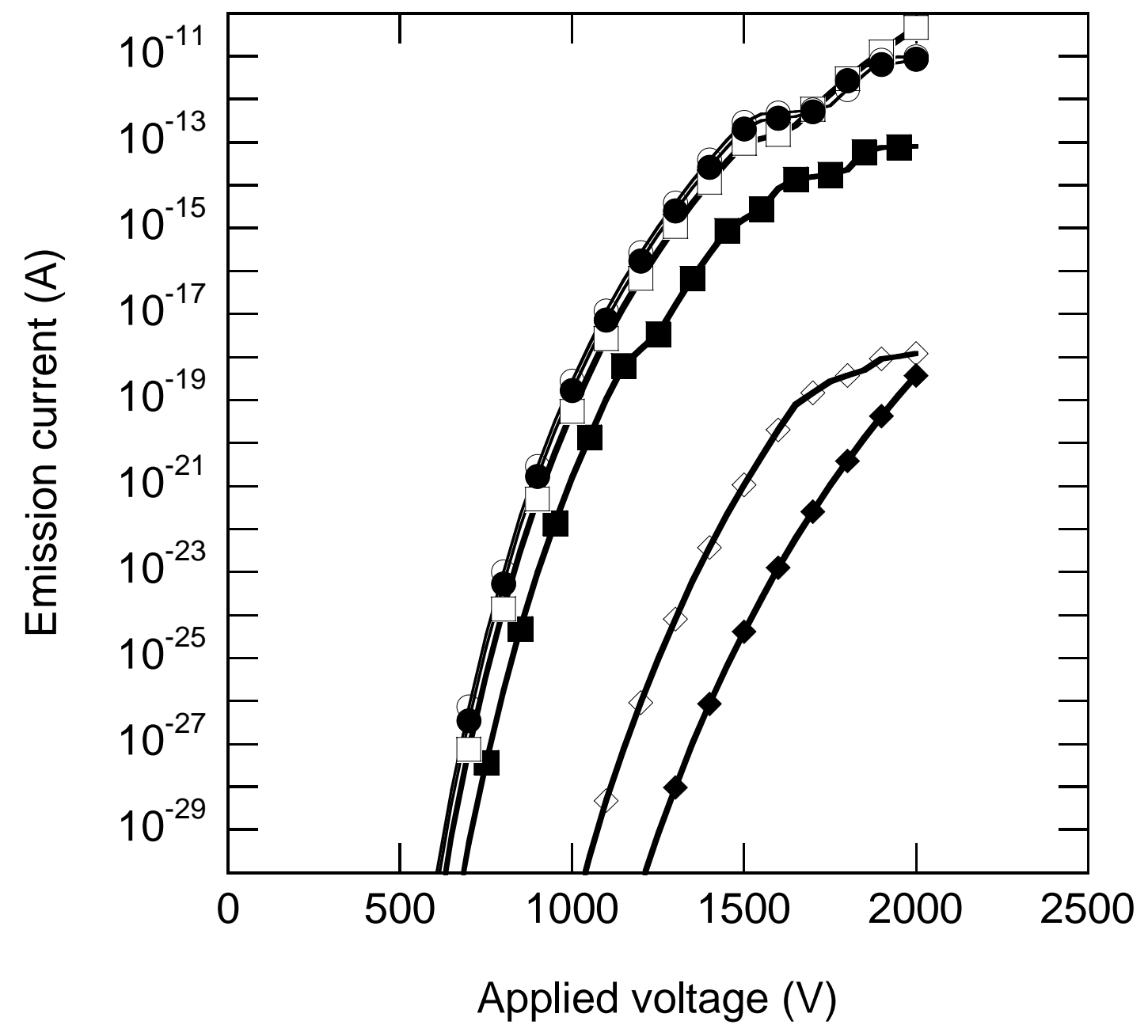

Figure 7 Carey 